\title{
Pengaruh Curah Hujan dan Pemupukan terhadap Produksi Tebu (Saccharum officinarum L.) di Pabrik Gula Asembagus Kabupaten Situbondo
}

\author{
Effect of Rainfall and Fertilization on Sugarcane Production (Saccharum officinarum L.) in \\ Asembagus Sugar Factory Situbondo Regency
}

\author{
Dian Hartatie ${ }^{1 *}$, Ramadhan Taufika ${ }^{1}$, Prihat Brillianti Achmad ${ }^{1}$ \\ ${ }^{1}$ Jurusan Produksi Pertanian, Politeknik Negeri Jember \\ *dian_hartatie@polije.ac.id
}

\begin{abstract}
ABSTRAK
Produksi tebu dipengaruhi oleh berbagai faktor. beberapa faktor yang mempengaruhi adalah iklim dan pemupukan. Iklim, terutama curah hujan, dapat mempengaruhi produksi dan hasil tebu. Pemupukan merupakan kegiatan penambahan unsur hara dan unsur hara ke dalam tanah, namun pemupukan yang berlebihan tanpa melalui analisis tanah dan analisis daun akan berdampak negatif pada tanaman tebu. Kegiatan ini bertujuan untuk mengetahui hubungan antara curah hujan dan pemupukan, serta pengaruh keduanya terhadap produksi tebu di Pabrik Gula Asembagus Kabupaten Situbondo. Penelitian ini dilaksanakan di Pabrik Gula Asembagus Kabupaten Situbondo pada bulan Agustus 2019 sampai dengan Desember 2019. Analisis statistik menggunakan analisis korelasi dan regresi linier berganda. Hasil analisis statistik menunjukkan bahwa curah hujan pada produksi tebu berkorelasi positif dengan tingkat hubungan kuat dan pemupukan terhadap produksi tebu berkorelasi positif dengan tingkat hubungan rendah. Hasil analisis regresi linier berganda menunjukkan bahwa curah hujan dan pemupukan berpengaruh nyata terhadap produksi tebu di Pabrik Gula Asembagus Kabupaten Situbondo.
\end{abstract}

Kata kunci - Curah Hujan, Produksi Tebu, Pabrik Gula Asembagus, Kabupaten Situbondo

\begin{abstract}
Sugarcane production influence by various factors. some factors that influence are climate and fertilization. Climate, especially rainfall, can affect sugarcane production and yield of sugarcane. Fertilization is an activity of adding nutrients and nutrients to the soil, but excessive fertilization without going through soil analysis and leaf analysis will have a negative impact on sugarcane. This activity aims to determine the relationship between rainfall and fertilization, and the effect of the both of them on sugarcane production at the Asembagus Sugar Factory, Situbondo Regency. This research was conducted at the Asembagus Sugar Factory, Situbondo Regency in August 2019 until December 2019. The statistical analysis use correlation analysis and multiple linear regression. The results of statistical analysis show that rainfall on sugarcane production has a positive correlation with the level of a strong relationship and fertilization to sugarcane production has a positive correlation with a low level of relationship. The results of multiple linear regression analysis showed that rainfall and fertilization significantly affected sugarcane production at the Asembagus Sugar Factory, Situbondo Regency.
\end{abstract}

Keywords - Rainfall, Sugarcane Production, Asembagus Sugar Factory, Situbondo Regency 


\section{Introduction}

Gula menjadi salah satu kebutuhan pokok yang sangat penting bagi masyarakat dan industri yang pada saat ini masih terus menjadi permasalahan. Hal ini karena industri gula dalam negeri belum mampu memenuhi permintaan masyarakat. Menurut Rukmana (2015) proyeksi kebutuhan gula nasional pada tahun 2015 sebesar 5,77 juta ton, tahun 2016 sebesar 5,97 juta ton, tahun 2017 sebesar 6,17 juta ton, tahun 2018 sebesar 6,39 juta ton. Sementara itu produksi gula akan mengalami peningkatan diperkirakan pada tahun 2015 sebesar 2,95 juta ton, tahun 2016 sebesar 2,98 juta ton, tahun 2017 sebesar 3,03 juta ton, tahun 2018 sebesar 3,09 juta ton. Peningkatan produksi gula tersebut juga masih belum bisa memenuhi jumlah permintaan gula masyarakat. Peningkatan permintaan gula dalam negeri harus diimbangi dengan adanya peningkatan produksi tebu. Produksi tebu akan meningkat sejalan dengan meningkatnya nilai rendemen tebu. Penurunan rendemen tebu dapat disebabkan oleh beberapa hal seperti proses budidaya, kualitas bibit yang rendah, iklim yang terjadi serta pasokan unsur hara ke dalam tanah.

Faktor iklim terutama curah hujan turut menentukan pertumbuhan dan produksi tebu, yang berpengaruh terhadap kadar gula atau nira tebu, serta mempengaruhi besaran produksi gula. Irianto dan Suciantini (2006) menyatakan bahwa kejadian anomali iklim di Indonesia telah terbukti mempengaruhi produksi pertanian. Karena kaitannya dengan ketersediaan air, jika terjadi anomali iklim terutama yang menyebabkan kekeringan di Indonesia, maka tanaman pangan yang paling terpengaruh adalah tanaman-tanaman yang membutuhkan banyak air dalam satu daur hidupnya (seperti padi), sehingga ketika musim bergeser maju atau mundur dari yang dijadwalkan, tanaman akan mengalami kekeringan. Untuk itu karakteristik perubahan anomali iklim perlu dikuantifikasi besaran (magnitude) agar dampak anomali iklim dapat diantisipasi lebih dini dan diminimalkan resikonya (Estiningtyas dkk. 2008). Perubahan iklim yang terjadi menyebabkan pola curah hujan menjadi tidak menentu dan sangat berpengaruh terhadap musim tanam. Pertumbuhan tanaman tebu memerlukan perbedaan nyata antara musim hujan dan kemarau. Menurut Rukmana (2015) umumnya tanaman tebu membutuhkan curah hujan tahunan antara 1.000-1.300 mm/tahun. Selama masa vegetatif tebu membutuhkan banyak air, sedangkan pada akhir masa vegetatif atau menjelang tebu masak untuk dipanen maka tebu membutuhkan keadaan kering atau tidak ada hujan yang menyebabkan terhentinya pertumbuhan tebu dan memulai proses penimbunan sukrosa dalam batang tebu. Apabila curah hujan cukup tinggi maka kesempatan tanaman tebu untuk matang terus tertunda sehingga menyebabkan kadar gula atau nira tebu turun dan berakibat terhadap produksi gula rendah.

Selain faktor curah hujan, faktor utama yang mempengaruhi produksi tebu yaitu pemupukan. Rosdianingsih (2013) menyatakan bahwa pemupukan dalam budidaya tebu harus memperhatikan kebutuhan tanaman dan ketersediaan unsur hara dalam tanah, sehingga dosis pemupukan dalam setiap lokasi juga berbeda. Pada umumnya tanaman tebu membutuhkan 3 jenis pupuk yang berbeda yaitu ZA 8-9 Ku/Ha, SP36 2 Ku/Ha, dan KCl 2 Ku/Ha. Magandi dan Purwono (2019), menyatakan bahwa permasalahan yang dialami saat ini beberapa petani tebu mengaplikasikan pupuk yang lebih dari dosis anjuran dengan harapan hasil yang diperoleh dapat maksimal. Namun hal ini menjadi tidak efektif dan efisien. Pemupukan yang berlebih tanpa melalui analisis daun dan analisis tanah akan berdampak negatif pada tanaman tebu. Menurut Magandi dan Purwono (2019) pemupukan yang melebihi dosis dan tidak seimbang dapat menurunkan produktivitas maupun rendemen tebu serta akan berdampak juga terhadap lingkungan.

Penelitian ini masih belum banyak dilakukan oleh karena itu perlu dilakukan pengkajian mengenai pengaruh curah hujan dan pemupukan terhadap produksi tebu untuk mengetahui korelasi curah hujan dan pemupukan serta pengaruh keduanya terhadap produksi tebu di Pabrik Gula Asembagus Kabupaten Situbondo.

\section{Method}

Pelaksanaan kegiatan ini dilaksanakan pada bulan Agustus sampai dengan Desember 2019 yang bertempat di Pabrik Gula Asembagus 
- Kabopaten Situbondo dan Politeknik Negeri Jember. Alat yang digunakan meliputi notebook Lenovo Idealpad 310S-11IAP RAM 2,00 GB, kamera handphone Oppo A3S RAM 2,00 GB, peta lokasi Kabupaten Situbondo, buku tulis, bolpoin, dan kalkulator. Bahan yang digunakan meliputi data curah hujan di PG Asembagus dari tahun 2009 sampai 2018, data pemupukan di PG Asembagus dari tahun 2009 sampai 2018, dan data produksi tebu di Pabrik Gula Asembagus Kabupaten Situbondo dari tahun 2009 sampai 2018.

Metode analisis statistik yang digunakan dalam kegiatan ini yaitu korelasi dan regresi yang ada di program Microsoft Office Excel.

Prosedur penelitian meliputi perizinan ke Pabrik Gula Asembagus Kabupaten Situbondo.dan survey lokasi, perizinan dan administrasi, mengambil dan mengumpulkan data, input data dan menganalisis data, menarik kesimpulan.

Parameter yang digunakan dalam pengamatan ini adalah curah hujan ( $\mathrm{mm} / \mathrm{tahun}$ ), pemupukan (ton/tahun), dan produksi tebu (ton/tahun).

\section{Discussion}

3.1. Analisis Korelasi Curah Hujan dan Pemupukan Terhadap Produksi Tebu

Berdasarkan analisis menggunakan aplikasi Microsoft Excel dengan rumus = Correl (variabel X; variabel Y) diperoleh hasil sebagai berikut:

Table 1. Hasil Analisis Korelasi Curah Hujan dan Pemupukan Terhadap Produksi Tebu di Pabrik Gula Asembagus Kabupaten Situbondo.

\begin{tabular}{|c|c|c|c|c|}
\hline $\begin{array}{l}\text { Variabel } \\
\text { Terikat }\end{array}$ & $\begin{array}{l}\text { Variabel } \\
\text { Bebas }\end{array}$ & $\begin{array}{l}\text { Koefisien } \\
\text { Korelasi } \\
\text { (r) }\end{array}$ & $\begin{array}{l}\text { T- } \\
\text { hitung }\end{array}$ & $\begin{array}{l}\text { T-tabel } \\
5 \%\end{array}$ \\
\hline \multirow[t]{2}{*}{$\begin{array}{l}\text { Produksi } \\
\text { Tebu (Y) }\end{array}$} & $\begin{array}{l}\text { Curah } \\
\text { Hujan }\left(X_{1}\right)\end{array}$ & 0,726 & $2,984^{* *}$ & 2,101 \\
\hline & $\begin{array}{l}\text { Pemupukan } \\
\left(\mathrm{X}_{2}\right)\end{array}$ & 0,318 & $0,949^{\mathrm{ns}}$ & \\
\hline
\end{tabular}

Keputusan: Tolak H0 apabila T-hitung $\geq$ T-tabel

Keterangan:

** = signifikan pada taraf signifikansi 0,05

ns $\quad$ tidak signifikan
Berdasarkan Tabel 1. menunjukkan bahwa hubungan curah hujan terhadap hasil produksi tebu di Pabrik Gula Asembagus Kabupaten Situbondo. selama 10 tahun terakhir dari tahun 2009-2018 berkorelasi positif dengan nilai koefisien korelasi atau $r$ sebesar 0,726 dan memiliki tingkat hubungan yang kuat. Untuk menguji hasil korelasi tersebut signifikan atau tidak maka harus diuji dengan membandingkan nilai T-hitung dengan nilai T-tabel. Dari hasil tersebut diperoleh nilai T-hitung yaitu 2,984 dan nilai T-tabel dengan taraf signifikansi 0,05 yaitu 2,101 . Berdasarkan perbandingan tersebut nilai T-hitung lebih besar daripada T-tabel yang artinya tolak H0. Hal ini menunjukkan bahwa terdapat hubungan yang signifikan antara curah hujan dengan produksi tebu di PG Asembagus.

Air merupakan komponen fisik yang sangat penting dan diperlukan dalam jumlah banyak untuk pertumbuhan dan perkembangan tanaman selain itu air berfungsi sebagai pelarut hara, penyusun protoplasma, bahan baku fotosintesis dan untuk proses metabolisme tanaman (Kurniawan dkk. 2014). Menurut Hartanto dkk. (2018) tanaman tebu membutuhkan banyak air pada masa pertumbuhan tanaman atau masa vegetatif yang berperan untuk meningkatkan bobot batang tebu yang meliputi diameter batang dan tinggi batang. Oleh karena itu pengaturan air pada budidaya tanaman tebu harus dipenuhi sesuai dengan kebutuhan tanaman sehingga nantinya akan meningkatkan hasil produksi tebu.

Hasil analisis korelasi pada variabel pemupukan terhadap produksi tebu di PG Asembagus menunjukkan hubungan positif dimana nilai koefisien korelasi atau $r$ sebesar 0,318 namun memiliki tingkat hubungan yang rendah. Hal ini dikuatkan juga dengan uji signifikansi korelasi diperoleh hasil nilai $\mathrm{T}$ hitung yaitu 0,949 dan nilai T-tabel dengan taraf signifikansi 0,05 yaitu 2,101. Berdasarkan perbandingan tersebut nilai T-hitung lebih kecil daripada T-tabel yang artinya terima H0. Hal ini menunjukkan bahwa tidak terdapat hubungan yang signifikan antara pemupukan terhadap produksi tebu di Pabrik Gula Asembagus Kabupaten Situbondo.

Pemupukan pada dasarnya adalah kegiatan menambah unsur hara bagi tanaman untuk tumbuh dan berkembang dengan baik. Menurut 
Permana dkk. (2015) suplai unsur hara yang sesuai dengan kebutuhan tanaman dapat meningkatkan jumlah anakan. Meningkatnya jumlah anakan tebu berbanding lurus dengan meningkatnya produksi tanaman tebu, hal ini dikarenakan jika anakan semakin banyak maka populasi dalam 1 tanaman akan semakin meningkat. Diana dkk. (2017) menyatakan bahwa penambahan bobot batang tebu dipengaruhi oleh penambahan pupuk NPK. Oleh karena, itu variabel pemupukan memiliki hasil korelasi positif terhadap produksi tebu di Pabrik Gula Asembagus Kabupaten Situbondo.

\subsection{Analisis Regresi Linier Berganda Curah Hujan dan Pemupukan Terhadap Produksi Tebu}

Berdasarkan hasil uji analisis regresi linier berganda curah hujan dan pemupukan terhadap produksi tebu di Pabrik Gula Asembagus Kabupaten Situbondo. memiliki persamaan regresi yaitu:

$$
Y=26969,238+9,142 X_{1}+67,681 X_{2}
$$

Persamaan regresi di atas menjelaskan bahwa jika kedua variabel (variabel curah hujan dan variabel pemupukan) adalah konstan atau bernilai 0 maka produksi tebu mencapai 26969,238 ton. Apabila variabel curah hujan meningkat sebesar 1 satuan, maka variabel produksi tebu akan meningkat sebesar 9,142 dan apabila variabel pemupukan meningkat sebesar 1 satuan, maka variabel produksi tebu akan meningkat sebesar 67,681 dengan kata lain apabila ada peningkatan curah hujan dan pemupukan maka produksi tebu juga akan meningkat.

Table 2. Tabel Anova Analisis Regresi Linier Berganda Curah Hujan dan Pemupukan Terhadap Produksi Tebu di PG Asembagus

\begin{tabular}{lllllll}
\hline & df & SS & MS & F-hitung & F-tabel5\% & Significance F \\
\hline Regression & 2 & 116762506,890 & 58381253,445 & $6,740^{* *}$ & 4,737 & 0,023 \\
Residual & 7 & 60636412,154 & 8662344,593 & & & \\
Total & 9 & 177398919,044 & & & & \\
\hline
\end{tabular}

Keputusan: Tolak H0 apabila F-hitung $\geq$ F-tabel atau Significance F $<0,05$

Keterangan:

$* *$ = signifikan pada taraf signifikansi 0,05

Uji F atau dikenal dengan uji model regresi yaitu uji yang dilakukan untuk melihat pengaruh semua variabel bebas secara bersamaan atau simultan terhadap variabel terikatnya dan bisa juga digunakan untuk menguji model regresi yang dibuat signifikan atau non signifikan. Setelah dilakukan perhitungan anova diperoleh hasil F-hitung sebesar 6,740 dan nilai F-tabel 4,737. Berdasarkan hal tersebut diketahui nilai Fhitung lebih besar daripada F-tabel maka keputusannya adalah tolak H0 yang artinya curah hujan dan pemupukan secara simultan berpengaruh terhadap produksi tebu di Pabrik Gula Asembagus Kabupaten Situbondo. Berdasarkan Tabel 4.3 nilai signifikansi $\mathrm{F}$ juga lebih kecil dari 0,05 maka keputusannya adalah tolak H0 yang artinya curah hujan dan pemupukan secara simultan berpengaruh signifikan terhadap produksi tebu di Pabrik Gula Asembagus Kabupaten Situbondo.

Pupuk yang disebar pada lahan tebu harus memiliki daya larut yang baik agar hara dalam pupuk dapat terserap oleh akar tanaman. Air sebagai pelarut pupuk berfungsi sebagai media gerak akar untuk menyerap unsur hara dalam tanah, serta mendistribusikannya ke seluruh bagian organ tanaman (Hardjowigeno, 2015). Fungsi pupuk pada umumnya yaitu memberikan nutrisi untuk tanaman dan memperbaiki kualitas serta kuantitas tanaman. Kegiatan pemupukan di Pabrik Gula Asembagus Kabupaten Situbondo. dilakukan pada saat penanaman tebu di bulan Mei-Juli. Menurut Hardjowigeno (2015) agar pupuk dapat diserap optimal oleh tanaman maka 
harus memperhatikan berbagai aspek antara lain jenis pupuk, dosis pupuk, jenis tanah, waktu pemupukan, cara pemupukan serta faktor-faktor yang mempengaruhi penyerapan pupuk pada tanaman. Cahyani dkk. (2016) menyatakan bahwa pertumbuhan batang tanaman tidak hanya dipengaruhi oleh unsur hara saja tetapi dapat dipengaruhi oleh lingkungan tumbuh seperti ketersediaan air. Oleh karena itu ketersediaan air dan pemupukan yang cukup merupakan hal yang harus diperhatikan dalam upaya peningkatan hasil tanaman.

Model regresi yang baik dapat dilihat dari besarnya nilai koefisien determinasi, semakin besar nilai koefisien determinasi maka semakin besar pula kontribusi suatu variabel bebas terhadap variabel terikatnya. Kemudian setelah diperoleh nilai regresi langkah selanjutnya adalah dilakukan proses perhitungan koefisien determinasi atau $\mathrm{R}^{2}$ untuk mengukur seberapa besar proporsi variabel $\mathrm{X}$ yang mempengaruhi variabelY.

Hasil uji analisis regresi linier berganda curah hujan dan pemupukan terhadap produksi tebu di Pabrik Gula Asembagus Kabupaten Situbondo.memiliki nilai koefisien determinasi $\mathrm{R}^{2}=0,658$ yang artinya proporsi atau kontribusi curah hujan dan pemupukan sebanyak $65,8 \%$ berpengaruh terhadap produksi tebu di Pabrik Gula Asembagus Kabupaten Situbondo dan sisanya sebesar $34,2 \%$ berasal dari pengaruh variabel lain seperti varietas tebu, masa tanam tebu, dan jenis tanah yang tidak dimasukkan ke dalam model regresi. Apabila nilai koefisien determinasi atau $\mathrm{R}^{2}$ mendekati angka 1 maka kontribusi curah hujan dan pemupukan berpengaruh terhadap produksi tebu di Pabrik Gula Asembagus Kabupaten Situbondo.

Table 3. Hasil Analisis Regresi Linier Berganda Curah Hujan dan Pemupukan Terhadap Produksi Tebu di Pabrik Gula Asembagus Kabupaten Situbondo.

\begin{tabular}{lrlll}
\hline & Koefisien & T-hitung & T-tabel 5\% & P-value \\
\hline Intercept & 26969,238 & $6,681^{* *}$ & 2,306 & 0,000 \\
Curah Hujan (X1) & 9,142 & $3,377^{* *}$ & & 0,012 \\
Pemupukan (X2) & 67,681 & $1,641^{\text {ns }}$ & & 0,145 \\
\hline
\end{tabular}

Keputusan: Tolak H0 apabila T-hitung $\geq \mathrm{T}$-tabel atau P-value $<0,05$

Keterangan:

** = signifikan pada taraf signifikansi 0,05

$\mathrm{ns}=$ tidak signifikan

Setelah dilakukan perhitungan anova maka dilanjutkan dengan Uji Parsial (Uji T). Uji T yaitu uji yang dilakukan untuk melihat bagaimana pengaruh masing-masing variabel bebas terhadap variabel terikatnya secara sendirisendiri atau parsial. Berdasarkan Tabel 4.4 di atas diketahui T-hitung dari variabel curah hujan mempunyai nilai 3,377. Karena nilai T-hitung 3,377 lebih besar daripada T-tabel 2,306 maka dapat disimpulkan bahwa curahhujan berpengaruh terhadap produksi tebu. Hal ini juga dikuatkan dengan nilai P-value pada variabel curah hujan sebesar 0,012 yang mana lebih kecil daripada taraf signifikansi 0,05 yang artinya apabila P- value lebih kecil daripada 0,05 maka keputusannya tolak $\mathrm{H} 0$ atau dengan kata lain terdapat pengaruh curah hujan terhadap produksi tebu di Pabrik Gula Asembagus Kabupaten Situbondo.

Tanaman memerlukan air dari tanah dan $\mathrm{CO} 2$ dari udara untuk membentuk gula dan karbohidrat dalam proses fotosintesis serta sebagai bahan penyusun sel-sel tanaman. Menurut Hardjowigeno (2015) umumnya tanaman terdiri atas $80 \%$ air dan $20 \%$ lainnya merupakan bahan kering. Berdasarkan data curah hujan di Pabrik Gula Asembagus Kabupaten Situbondo. pada tahun 2009 sampai dengan 2018 nilai rata-rata curah hujan mencapai 1019,7 $\mathrm{mm} / \mathrm{tahun}$. Hal ini sesuai dengan pernyataan Rukmana (2015) yang menyatakan bahwa tanaman tebu membutuhkan curah hujan tahunan antara 1.000-1.300 mm untuk pertumbuhan dan perkembangan tebu di daerah dataran rendah. 
Selain itu, penyebaran hujannya harus sesuai dengan fase-fase pertumbuhan tebu. Misalnya tanaman tebu membutuhkan suplai air yang cukup banyak pada fase perkecambahan dan pertumbuhan tunas (masa vegetatif) dan saat memasuki fase pemasakan batang (masa generatif) maka dibutuhkan lingkungan yang kering dan sedikit air agar proses pemasakan berjalan dengan baik. Apabila terjadi hujan terus menerus saat tebu memasuki fase generatif, maka tebu terus tumbuh dan tidak akan terjadi proses kemasakan tebu dan juga dapat berakibat turunnya rendemen tebu. Rata- rata kebutuhan curah hujan bulanan yang ideal di wilayah pertanaman tebu adalah $200 \mathrm{~mm} / \mathrm{bulan}$ pada 5-6 bulan berturut- turut, $125 \mathrm{~mm} / \mathrm{bulan}$ pada 2 bulan transisi, dan kurang dari $75 \mathrm{~mm} /$ bulan pada $4-5$ bulan berturut-turut. Oleh karena itu curah hujan sebagai penyedia air dalam tanah sangat berpengaruh terhadap pertumbuhan vegetatif tanaman tebu misalnya tinggi batang, diameter batang, dan jumlah anakan yang nantinya akan menghasilkan hasil produksi yang baik.

Sedangkan pada variabel pemupukan nilai T-hitung sebesar 1,641 dan nilai T-tabel 2,306. Karena nilai T- hitung variabel pemupukan lebih kecil daripada T-tabel sehingga dapat disimpulkan bahwa variabel pemupukan tidak ada pengaruh terhadap produksi tebu. Nilai Pvalue variabel pemupukan sebesar 0,145 nilai tersebut lebih besar daripada taraf signifikansi 0,05 sehingga dapat disimpulkan bahwa variabel pemupukan tidak berpengaruh terhadap produksi tebu di Pabrik Gula Asembagus Kabupaten Situbondo.

Tujuan pemupukan antara lain untuk meningkatkan kesuburan tanah sehingga kesuburan tanah menjadi stabil serta dapat meningkatkan daya tahan tanaman terhadap penyakit. Selain itu pemupukan juga bermanfaat untuk melengkapi unsur hara yang ada di dalam tanah sehingga kebutuhan nutrisi tanaman dapat terpenuhi dan diharapkan akan mencapai produksi tanaman yang maksimal. Pemupukan pada tanaman tebu mengedepankan prinsip pemupukan berimbang, yaitu mengaplikasikan pupuk pada tanah sesuai dengan kebutuhan tanaman dengan mempertimbangkan kadar hara dalam tanah dan juga hara residu.

Pemupukan yang tepat didasarkan oleh hassil analisis tanah dan analisis tanaman.
Kasniari dan Supadma (2007) menyatakan bahwa setiap pempukan dengan dosis yang diberikan akan mempengaruhi besar kecilnya kandungan dalam hara tersebut, tetapi belum dapat dijamin bahwa semakin besar dosis yang diberikan akan semakin meningkatkan pertumbuhan tanaman. Hal ini dikarenakan tanaman memiliki batas dan penyerapan hara untuk kebutuhan hidupnya. Menurut Poernomo (2004) tanaman tebu membutuhkan 3 jenis pupuk yang berbeda yaitu pupuk ZA 8-9 Ku/Ha, SP36 $2 \mathrm{Ku} / \mathrm{Ha}$, dan $\mathrm{KCl} 2 \mathrm{Ku} / \mathrm{Ha}$ namun pemupukan di PG Asembagus terdapat sedikit perbedaan dosis pupuk yang digunakan yaitu pupuk ZA $8 \mathrm{Ku} / \mathrm{Ha}$, SP36 1,5 Ku/Ha, dan $\mathrm{KCl}$ $2,5 \mathrm{Ku} / \mathrm{Ha}$. Pemberian pupuk yang tidak sesuai juga menjadi salah satu faktor rendahnya pengaruh pemupukan terhadap hasil produksi tebu. Hal ini disebabkan karena terdapat beberapa ion-ion yang sulit untuk diserap tanaman, sehingga tanaman tidak menyerap semua unsur hara yang ada di dalam pupuk. Menurut Hardjowigeno (2015) unsur hara N diserap dalam bentuk $\mathrm{NH}+$ dan $\mathrm{NO}$-, unsur hara $\mathrm{P}$ diserap dalam bentuk H2PO4- dan HPO 2-, dan unsur hara $\mathrm{K}$ diserap dalam bentuk $\mathrm{K}+$. Menurut Cahyani dkk. (2016) pada pemupukan $\mathrm{N}$ sebagian hara $\mathrm{N}$ hilang melalui proses denitrifikasi $(5-30 \%)$, pencucian dalam bentuk NO - (5-20\%), dan erosi serta hilang melalui penguapan dalam bentuk NH3.

Faktor lain yang menjadikan pemupukan tidak berpengaruh terhadap produksi tebu yaitu pH tanah. Menurut Rukmana (2015) tebu dapat tumbuh pada $\mathrm{pH}$ tanah berkisar antara 6-7,5 namun $\mathrm{pH}$ tanah di PG Asembagus lebih tinggi yaitu 7,96. Menurut Hardjowigeno (2015) pada tanah alkalis unsur $\mathrm{P}$ tidak dapat diserap oleh tanaman karena difiksasi oleh Ca. Selain itu lahan HGU di PG Asembagus berdekatan dengan pantai sehingga memiliki kadar garam dalam tanah yang tinggi. Menurut Rukmana (2015) kadar garam yang terlalu tinggi dapat menjadikan racun pada tanaman serta nira tebu akan susah mengkristal. Jenis tanah juga dapat mempengaruhi penyerapan pupuk.

Tanah di HGU Pabrik Gula Asembagus Kabupaten Situbondo. memiliki jenis tanah Regosol. Menurut Hardjowigeno (2015) jenis tanah Regosol umumnya bertekstur pasir lebih dari $60 \%$ serta memiliki struktur dan konsistensi 
lepas. Tanah yang memiliki struktur lepas atau porous seperti tanah berpasir sangat mudah merembeskan air yang mengangkut unsur hara sehingga hara yang dibutuhkan oleh tanaman tidak terjangkau oleh akar (Lingga dan Marsono, 2006).

\section{Conclusion}

Berdasarkan hasil penelitian dan analisis data dapat disimpulkan bahwa:

a. Hasil analisis korelasi menunjukkan bahwa curah hujan terhadap produksi tebu di PG Asembagus memiliki korelasi positif dengan tingkat hubungan yang kuast dan pemupukan terhadap produksi tebu di PG Asembagus memiliki korelasi positif dengan tingkat hubungan yang rendah.

b. Hasil analisis regresi linier berganda menunjukkan curah hujan dan pemupukan secara simultan berpengaruh signifikan terhadap produksi tebu di PG Asembagus.

\section{References}

[1] Badan Pusat Statistik. 2008. Data Wilayah dan Lahan Kabupaten Situbondo. https://bptsitubondo.files.wordpress.com/2008/11/datawilayah-dan- lahan.pdf. [24 Juli 2019]

[2] Cahyani, S., A. Sudirman, dan A. Azis. 2016. "Respons Pertumbuhan Vegetatif Tanaman Tebu (Saccharum officinarum L.) Ratoon 1 terhadap Pemberian Kombinasi Pupuk Organik dan Pupuk Anorgani”. Dalam Jurnal Agro Industri Perkebunan. 4(2): 69-78.

[3] Diana, N. E., Sujak, dan Djumali. 2017. "Efektivitas Aplikasi Pupuk Majemuk NPK Terhadap Produktivitas dan Pendapatan Petani Tebu". Dalam Buletin Tanaman Tembakau, Serat \& Minyak Industri. 9(2):42-52.

[4] Estiningtyas, W., E. Surmaini, dan K. S. Hariyanti. 2008. "Penyusunan Skenario Masa Tanam Berdasarkan Prakiraan Curah Hujan di Sentra Produksi Pangan”. Dalam Jurnal Meteorologi Dan Geofisika. 9(1): 41-53.

[5] Hardjowigeno, S. 2015. Ilmu Tanah. Jakarta: Akademika Pressindo.

[6] Hartanto, S., Irsal, A. Barus. 2018.“Tanggap Pertumbuhan Bibit Tebu Merah (Saccharum officinarum L.) Asal Bud Set terhadap Pemangkasan dan Frekuensi Penyiraman". Dalam Jurnal Pertanian Tropik. 5(1):136-146.
[7] Indrawanto, C., Purwono, Siswanto, M. Syakir, dan W. Rumini. 2010. Budidaya dan Pasca Panen Tebu. Jakarta: EKSA Media.

[8] Irianto, G. dan Suciantini. 2006. "Anomali Iklim: Faktor Penyebab, Karakteristik, dan Antisipasinya." Dalam Jurnal Iptek Tanaman Pangan. (2): 101-120

[9] Kasniari, D. N. dan A. A. N. Supadma. 2007. "Pengaruh Pemberian Beberapa Dosis Pupuk (N, P, K) dan Jenis Pupuk Alternatif Terhadap Hasil Padi (Oryza sativa L.) dan Kadar N, P, K Inceptisol Selemadeg, Tabanan." Dalam Jurnal Agritrop. 26(4):168-176.

[10] Kurniawan, B. A., S. Fajriani, dan Ariffin. 2014. "Pengaruh Jumlah Pemberian Air Terhadap Respon Pertumbuhan dan Hasil Tanaman Tembakau (Nicotiana Tabaccum L.)". Dalam Jurnal Produksi Tanaman. 2.(1): 59-64.

[11] Lingga, P. Dan Marsono. 2006. Petunjuk penggunaan pupuk. Jakarta: Penebar Swadaya.

[12] Magandi, F. I. dan Purwono. 2019. "Korelasi Dosis Pemupukan Nitrogen terhadap Produktivitas dan Rendemen Tebu (Saccharum officinarum L.)". Dalam Jurnal Bul. Agrohorti. 7(2): 224-229.

[13] Munawar, A. 2011. Kesuburan Tanah dan Nutrisi Tanaman. Bogor: IPB Press.

[14] Permana, A. D., M. Baskara, dan E. Widaryanto. 2015. "Pengaruh Perbedaan Umur Bibit Single Bud Planting dengan Pemupukan Nitrogen pada Pertumbuhan Awal Tanaman Tebu (Saccharum Officinarum L.)". Dalam Jurnal Produksi Tanaman. 3(5): $424-432$.

[15] Poernomo, D. 2004. Buku Pintar Sinder Kebun. Jatiroto: PT. Perkebunan Nusantara.

[16] Pramuhadi, G. 2010. "Faktor Iklim Pada Budidaya Tebu Lahan Kering”. Dalam Artikel Pangan. 19(4): 331-344.

[17] Rosdianingsih, D. 2013. Budidaya Tebu (Saccharum officinarum L.) Lahan Kering di PG. Madukismo PT. Madubaru Yogyakarta dengan Aspek Khusus Pemupukan Beberapa Kategori Tanaman Tebu Lahan Kering. Skripsi. Fakultas Pertanian Institut Pertanian Bogor.

[18] Rosmarkam, A. dan N. W. Yuwono. 2002. Ilmu Kesuburan Tanah. Yogyakarta: Kanisius.

[19] Rukmana, R. 2015. Untung Selangit dari Agribisnis Tebu. Yogyakarta: Lily Publisher. 